\title{
Teaching with LEEMUSICA/READMUSIC in Higher Education: Perception and Improve in Music Education ${ }^{\dagger}$
}

\author{
Rosario Castanon-Rodríguez \\ Department of Didactic of Music, Faculty of Education, Universidad de Valladolid, Paseo de Belen, 1, \\ 47011 Valladolid, Spain; mariarosario.castanon@uva.es; Tel.:+34-983183852 \\ + Presented at the 2nd Innovative and Creative Education and Teaching International Conference \\ (ICETIC2018), Badajoz, Spain, 20-22 June 2018.
}

Published: 12 December 2018

\begin{abstract}
The present work tries to reflect the student perception about their music education through the application of two tests in the classroom with university students at 3rd and 4th year of the Grade of Teacher at the Faculty of Education in the University of Valladolid. They have been realized at the beginning of the year the first one and at the end of the first semester of the academic year 2017/18. The first one concerns their previous formation in music (school and High school as well as formal/unformal music education-conservatories and schools of music - included their perception about the acquisition of basic music skins. The second test ask them specifically about their perception of improve of those skills (music language, tuning, playing instruments, aural education, didactic of music and use of ICT) after their formation in Higher Education with Leemúsica/Readmusic methodology.
\end{abstract}

Keywords: music education; didactic of music; music skills; higher education

\section{Introduction}

LEEMUSICA/READMUSIC is an innovative methodology developed at the Faculty of Education of the University of Valladolid (Spain) to introduce music language at early ages (from 3 to 5 years old) at pre-primary schools. It is recognized as a Project of Teaching Innovation by the University of Valladolid and many different departments are involved-Psychology, Pedagogy, and Arts. The Computer Engineering School is also collaborating with us in the development of educational applications for PC and Android systems.

Many pre-primary and primary schools are also involved in this project in order to observe, take in the practice, request and analyze data results and improve all the methodology in those first steps of education.

Leemúsica/Readmusic is a didactical application designed for use by regular teachers to introduce musical language at early ages ( 3 to 5 years old) as a part of the school curriculum. It is based on theoretical similarities with other linguistic acquisitions - mathematics and oral languagepostulated by Juslin \& Lukka, 2003 [1]; McMullen \& Saffran, 2004 [2]; Schön,Magne \& Besson, 2004 [3]; and early development of reading and writing processes studies by Stanley \& Hudges, 1997 [4]; Anvari, Trainor, Woodside \& Levy, 2002 [5].

Teachers formation in the use of the methodology is a significant requirement, and their perception of the utility and improve in their own personal music skills are needed. Satisfaction and motivation are required to make any educational change, and security in the procedures is basic before taking it to everyday classroom, mainly when music education introducing specific language is not required in the formal curriculum at this level. Understanding that global language 
development may include other symbols as mathematical or musical is the main objective in this higher education and giving to our students the pedagogical and methodological strategies to take it correctly to the school is our goal. Their perception of it is very important in order to the appliance or not of the methodology (voluntary) in the next years during their professional life.

\section{Materials and Methods}

Two tests have been completed by the university students of $3^{\text {rd }}$ year at the Grade of Teacher in Preschool Education in the Faculty of Education of the University of Valladolid. The first one, oriented to get information about their previous music education, the perception of quality and music skills developed, take place in September 2017 in the classroom. The second one, focused on satisfaction and improvement perception after have practiced with Leemusica/readmusic methodology, was realized in January 2018

The group age range is $20-25$ years old, with only 5 cases of more than 40 . Participation was voluntary in the second test and was sent by digital support and collected when the students were very busy with their period of "Practicum" at school with meant finally a decreasing number of disposable answers (71 students for the first test and 37 for the second one). $95 \%$ of them are female.

\section{Results}

\subsection{Before the Universty}

The previous formation, as shown below in Figure 1, reflects they have received music formation at school during six years at Primary school. Only 5 of them have a partial or uncomplete formation at primary school. And also a great majority has continued with music education on secondary school.

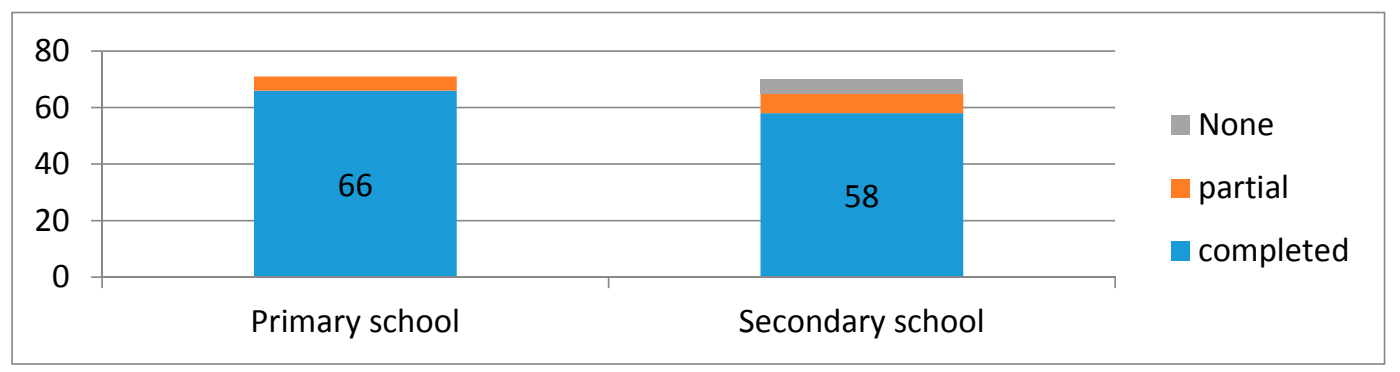

Figure 1. Music education at primary and secondary school.

Music education is compulsory at primary schools from1990 and it is offered to students from six to 12 years old. It continues with at least one more year at secondary school and should be extended for other two more years. The case of 5 students that has not received any music education at secondary school is because of their age over 40 .

Only a very few of them have received music education out from the school in a complementary formation as you can see in Figure 2, (only 1 student has studied in a conservatory and 6 of them at music schools). Wherever, a quite significant number has participated in music activities like choir, bands, guitar, family or theatre.

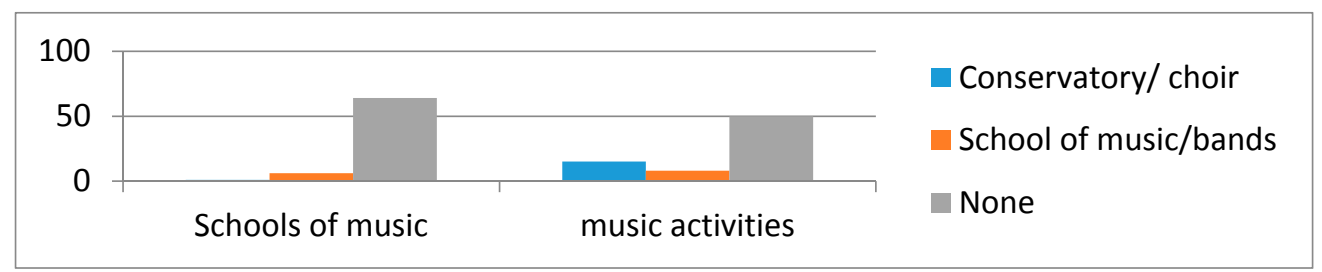

Figure 2. Music education out of school and music activities. 
Their perception of music education quality and satisfaction with seem to be quite acceptable (Figure 3).

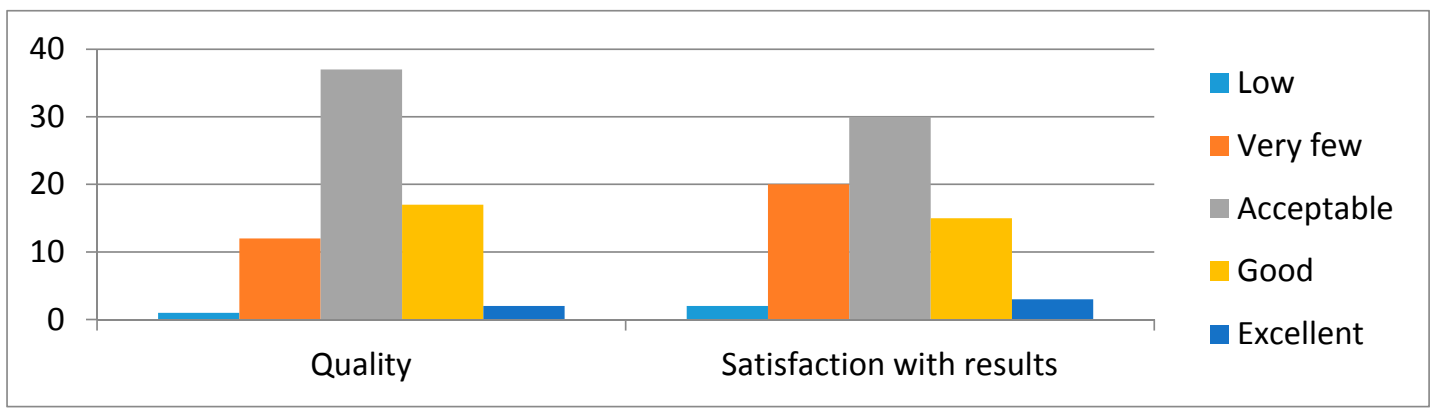

Figure 3. Perception of the quality and satisfaction with music education previously received.

When getting deeper in singular aspects of music education they seem to have acceptable levels of perception in singing and playing with melodic instruments, but quite uncompleted in harmony (basic chords), history of music and music language aspects (Figure 4).

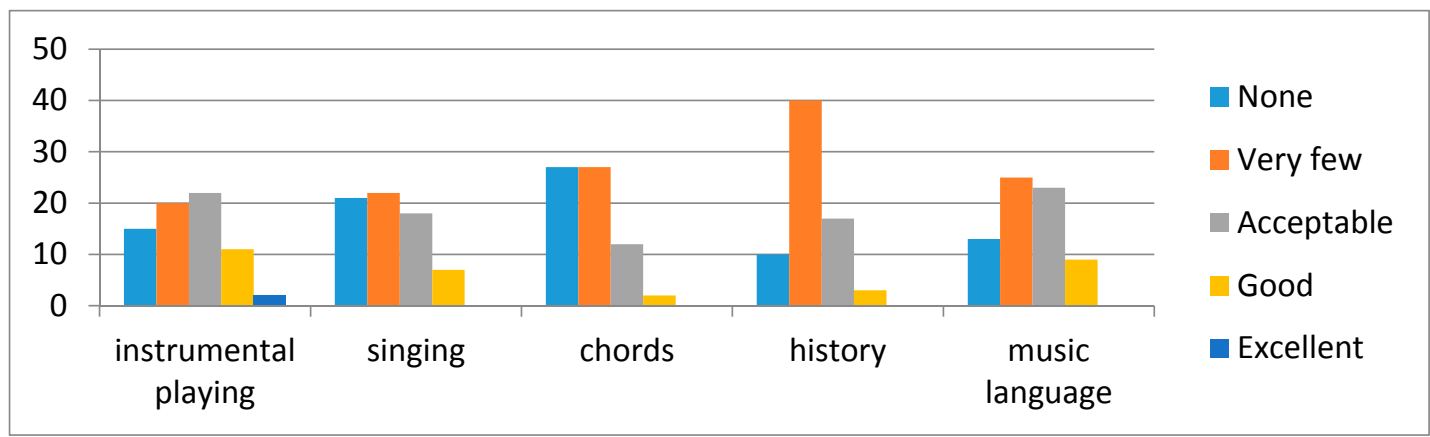

Figure 4. Perception of musical performance.

They feel more comfortable when playing a melodic instrument than singing, and even some of them qualifies its instrumental formation (recorder and Orff percussion) as excellent. In the opposite, historical aspects seem to have been not cared and students perceive them as unsatisfactory.

\subsection{At the University}

After have worked with Leemusica/readmusic at their university studies $(60 \mathrm{~h}$ of formation at 3rd. year of the Grade of Preschool Teacher) the level of satisfaction is significantly increased. Their satisfaction with teaching/learning process and pedagogical application to professional life with children is remarkable (Figure 5).

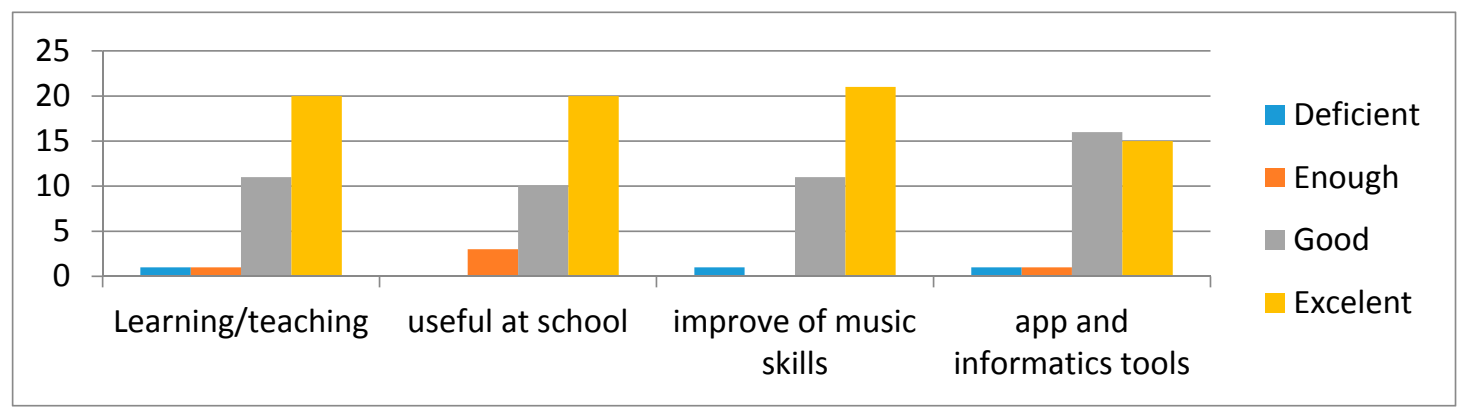

Figure 5. Perception with Leemusica/readmusic methodology at university.

Students seem to have improved significantly their security when tuning and playing instruments (metallophones-melody- and percussion-rhythm-). When performing in group, singing 
or playing the increasing of satisfaction level is notorious, giving to them an extra motivation (Figure 6).

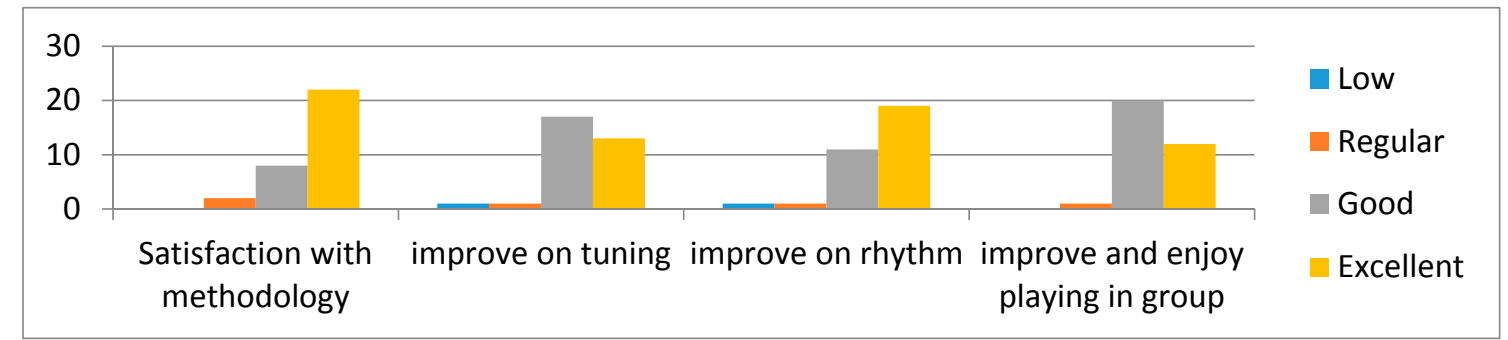

Figure 6. Satisfaction and improve of music skills with Leemusica/readmusic.

\section{Discussion and Conclusions}

Students come to university with a large previous music formation. But they don't seem to be very confident when playing or singing and they have several deficiencies in methodological skills to teach music to children. This formation has been mainly based on repetition and imitation, but not in a comprehensive or discovering procedure. It never leave place for repertory choice by themselves or taking decisions. It used to be imposed, not critical neither creative.

Even their perception of previous formation is acceptable, they don't feel comfortable when reading music by themselves, playing in group or singing alone. Those skills improve easily with a pedagogical review of strategies and tools used during the music performance and systematical practice.

New methodologies based on linguistic associations-introduced at early ages and linked to the global learning-are a well perceived innovation that provides to them motivation to improve their own performance skills. And give them some expectations of doing it in a different way than they received at school before university studies. Young teachers are expectant and interested in new methodologies and connected with school reality proposals.

Acknowledgments: Leemusica/Readmusic has been supported by two Research Programs by Junta de Castilla y León and University of Valladolid (2008-9 and 2010-12). From September 2017 it is recognized as an Innovation Project by the University of Valladolid (Spain).

\section{References}

1. Juslin, P.N.; Laukka, P. Communication of emotions in vocal expression and music performance: different channels, same code? Psychol. Bull. Am. Psychol. Assoc. 2003, 129, 770-814.

2. McMullen, E.; Saffran, J.R. Music and language: a developmental comparison. Music Percept. Interdiscip. J. 2004, 21, 289-311.

3. Schön, D.; Magne, C.; Besson, M. The music of speech: music training facilitates pitch processing in both music and language. Psycholophysiology 2004, 41, 341-439.

4. Stanley, J.M.; Hudges, J.E. Evaluation of an early intervention music curriculum for enhancing prereading/writing skills. Music Ther. Perspect. 1997, 15, 79-85.

5. Anvari, S.H.; Trainor, L.J.; Woodside, J.; Levy, B.A. Relations among musical skills, phonological processing, and early reading ability in preschool children. Exp. Child Psychol. 2005, 83, 11-113.

(C) 2018 by the authors. Licensee MDPI, Basel, Switzerland. This article is an open access article distributed under the terms and conditions of the Creative Commons Attribution (CC BY) license (http://creativecommons.org/licenses/by/4.0/) 